\title{
Statistical analyses for comparison of esophageal and hand-clipped samples from grazing trials
}

\author{
K.P. VOGEL, K.J. MOORE, AND B.E. JOHNSON
}

\section{Abstract}

Esophageal fistulated animals are used to collect samples of the forage being consumed by animals in grazing experiments. Four principal hypotheses (H) can be tested in esophageal trials: (1) esophageal samples are similar over treatments, (2) available forage is similar over treatments, (3) esophageal and available forage samples are similar, and (4) differential selection of diet did not occur among treatments. Because of the constraints of limited animal numbers, multiple latin-square or crossover designs in which the same animals are used to sample pastures during different periods of time are used to test $H 1$. Available forage is determined by collecting samples from the pastures over the duration of the study. The experimental design for these samples is a split-plot in time which is used to test $\mathbf{H}$ 2. Analyses of 1 set of samples (esophageal or available) using the experimental design for the other set is inappropriate. Since esophageal and available samples are paired within experimental units, paired $t$-tests can be used to test $H 3$ by treatment or averaged over treatments. $H 4$ can be tested by conducting an analysis of variance of esophageal minus available (or vice-versa) differences averaged over periods. Significant treatment effects indicate differential selection of diet among treatments occurred.

Key Words: diet selection, livestock preference, forage quality, experimental design

Esophageal fistulated ruminants are used in grazing trials to obtain samples of available forage consumed by the grazing animal (Van Dyne and Torrel 1964). Esophageal sampling is necessary because animals selectively graze pastures and rangelands when the amount of available forage exceeds their requirements (Allison 1985, t'Mannetje 1978). One common objective of studies conducted with esophageal fistulated animals is to compare the quality or composition of available forage with the quality or composition of forage selected by the grazing animal from pastures in which specific treatments have been applied (Barth and Kazzal 1971, Campbell et al. 1968, Coleman and Barth 1973). Comparative studies are typically conducted using forage samples collected by esophageal fistula and hand clipping. Since treatments are applied to pastures or enclosures, the pasture is the experimental unit (Brown and Waller 1986, Stroup et al. 1986). In order to estimate experimental error and to make valid tests of mean differences, the treatments must be replicated.

The design of grazing studies in which esophageal fistulated animals are used to collect samples of available forage from pastures on which specific treatments have been applied is often constrained by the number of fistulated animals available. Ideally, each specific treatment would be replicated by being applied to more than 1 pasture, each pasture would be stocked with more than 1 esophageal fistulated animal with animals randomly assigned to pastures, and samples from individual animals within each pasture would be composited to produce a representative

Authors are supervisory rescarch geneticist, research agronomist, USDA-ARS, and assistant professor, Agronomy Department, University of Nebraska, Lincoln 68583.

This is a contribution from the USDA/ARS and the Nebraska Agr. Exp. Sta., Lincoln. Published as paper 9105, Journal Series, Nebraska Agr. Exp. Sta.

The authors wish to thank W.W. Stroup, R.F. Mumm, and K.M. Eskridge, statisticians in the Biometry Department at the University of Nebraska, for their constructive reviews and suggestions.

Manuscript accepted 11 August 1990. sample for the experimental unit. The samples would then be collected during the grazing season. Stocking individual pastures with more than 1 esophageal fistulated animal is seldom done because of the high cost of developing these animals. Usually only 1 animal is stocked per pasture. If the same animal is left on the same pasture during the grazing season, it is not possible to determine if the results for that pasture are due to the treatment effect or to the individual behavior of the animal on that pasture; i.e., the effects of treatments and animals are confounded and valid statistical comparisons cannot be made among means. If multiple animals are used on each pasture but there is only 1 pasture per treatment (no replication of treatments), treatment and animal effects are again confounded and valid mean comparisons cannot be made.

Latin-square designs in which the same animals are used to sample pastures during different periods of time are frequently used to overcome the constraint imposed by limited number of animals. A problem arises when the investigator wishes to compare samples collected using fistulated animals with those collected by hand clipping. The hand-clipped samples are generally collected from pastures during each grazing period by randomly sampling each pasture. The appropriate experimental design for samples collected using hand clipping is a split-plot in time. Because the experimental designs used to collect the esophageal and handclipped samples are inherently different, comparison of esophageal and hand-clipped means is not straightforward.

The purpose of this paper is to describe appropriate statistical methods for analyzing data from studies for which esophageal and hand-clipped samples need to be compared. The statistical problems involved in analyzing data from experiments in which esophageal and hand-clipped samples are collected and compared were encountered by the senior author in a study in which grass strains were being compared.

\section{Methods}

The procedures discussed here are pertinent to experiments in which esophageal fistulated animals are used to measure differences among treatments which have been applied to pastures. These treatments may be fertilization, growth regulators, or other cultural practices, or they may be different species or cultivars of a species (Large et al. 1985). For the purpose of this paper, the term "treatment" is used to represent any of the different types of treatments which might be applied to pastures.

As an example, consider an experiment in which 3 treatments $(t)$ are randomly applied to 3 pastures in each of 3 separate blocks $(b)$ of pastures so that each pasture or enclosure is an experimental unit. There are 9 pastures or experimental units in the study. In this type of a study, the treatments are almost always fixed effects while the effects of animals are random.

\section{Esophageal Sampling}

Each pasture or experimental unit could be stocked with 1 or more esophageal fistulated animals and samples collected from individual animals within a pasture to produce a representative sample for that experimental unit (e.g., Coleman and Barth 1973). Use of multiple animals in individual pastures may provide for a better estimate of the mean value of the individual experimental units; it does not provide replicated experimental units which are 
Table 1. Analysis of variance and expected mean squares for Latin-squares design used to analyze esophageal fistula samples'.

\begin{tabular}{|c|c|c|c|c|}
\hline Source & df & Mean Square & $\mathrm{E}$ (Mean Square) ${ }^{2}$ & F-test \\
\hline Square(S) & $(s-1)$ & & $\sigma^{2}+s t \sigma_{\mathrm{A}(\mathrm{S})}^{2}+\mathrm{t}^{2} \sigma_{\mathrm{S}}^{2}$ & \\
\hline Animal(A)/Square & $\mathbf{s}(\mathbf{a}-1)$ & & $\sigma^{2}+s t \sigma_{A(S)}^{2}$ & \\
\hline Period(P) & $(p-1)$ & $\mathbf{M S}_{\mathbf{p}}$ & $\sigma^{2}+t \sigma_{\mathrm{SP}}^{2}+s t \Phi P$ & $\mathbf{M S}_{\mathbf{p}} / \mathbf{M S}_{\mathbf{S P}}$ \\
\hline Square $\times$ Period & $(s-1)(p-1)$ & $\mathbf{M S}_{\mathbf{S P}}$ & $\sigma^{2}+t \sigma_{\mathrm{SP}}^{2}$ & $\mathbf{M S}_{\mathrm{SP}} / \mathbf{M S}_{\mathrm{RES}}$ \\
\hline Treatment(T) & $(t-1)$ & $\mathbf{M S}_{\mathbf{T}}$ & $\sigma^{2}+t \sigma_{\mathrm{ST}}^{2} \mathrm{st} \Phi \mathrm{T}$ & $\mathbf{M S}_{\mathbf{T}} / \mathbf{M S}_{\mathbf{S T}}$ \\
\hline Square $\times$ Treatment & $(s-1)(t-1)$ & $\mathbf{M S}_{\mathrm{ST}}$ & $\sigma^{2}+t \sigma_{S T}^{2}$ & $\mathrm{MS}_{\mathrm{ST}} / \mathrm{MS}_{\mathrm{RES}}$ \\
\hline Residual/Square & $s(p-1)(t-2)$ & $\mathrm{MS}_{\mathrm{RES}}$ & $\sigma^{2}$ & \\
\hline
\end{tabular}

ITreatments and periods are fixed effects while the effects of animals and squares are considered random.

2Expected mean squares.

needed for valid tests of comparisons made between treatments. Consequently, increasing the number of animals per individual pasture will not, in itself, provide a means of detecting differences in quality due to treatments.

Valid comparisons can be made if a multiple Latin-square design or crossover design with Latin-squares in each replicate of the study is used (Federer 1955) as shown in Figure 1. With this design only 1 esophageal fistulated animal needs to be assigned to each pasture. In order to create the Latin-square, the grazing period is
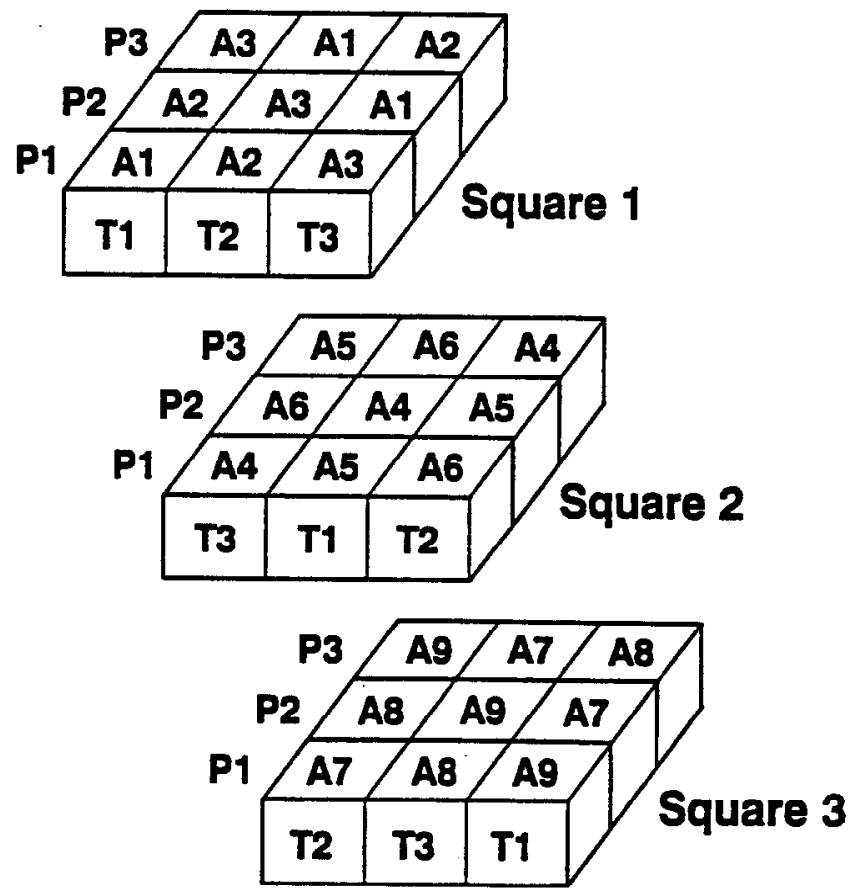

Fig. 1. Diagrammatic representation of a multiple Latin-square or crossover design with an orthogonal Latin-square in each square or replicate. $A=$ animals, $\mathbf{P}=$ periods, and $T=$ treatments. simply broken into $p$ grazing periods of equal duration. At the beginning of each period, which is considered fixed, each animal is rotated to a pasture treatment which it had not previously grazed. The order in which each animal is rotated to pasture treatments is assigned randomly. Each individual block of pastures then becomes a single Latin square (Fig. 1) with treatments and rows being columns and periods, respectively. Each animal-pasture combination is an unreplicated experimental unit in a single Latin-square. Hence, in this situation a single Latin-square does not permit testing for treatment differences since the individual animalpasture experimental units are unreplicated. Within a single Latinsquare, pastures are not replicated. Additional squares are needed to test for treatment difference. The minimum squares required is $t-1$ where $t$ is the number of treatments (Federer 1955, page 445). Since animals are rotated to different pastures within a single Latin-square each period, this design eliminates the animal $X$ period confounding effects that would exist if animals were assigned to the same pasture for the duration of the study. Another way of expressing the utility of the crossover design is that it provides a pattern for rotating fistulated animals in such a way that every treatment will be evaluated by every animal, thus removing animal difference from treatment difference.

An initial analysis of variance should be calculated using the form outlined in Table 1. It should be noted, however, that rows and columns, that is periods and treatments in this example, are crossed across all squares while animals are nested within squares. If the square $X$ treatment and the square $X$ period interactions are found to be nonsignificant by conducting an $F$ test with the residual mean square as the error term (Table 1), the sums of squares for these components can also be pooled with the within squares error sum of squares to produce a residual error sum of squares. Pooling the interaction components with error will result in additional degrees of freedom in the error term. The analysis of variance following pooling of interactions with error is shown in Table 2, and is essentially an analysis of variance for a crossover design (Federer 1955).

It is more likely that the square $X$ treatment and square $X$ period interactions will be nonsignificant when all blocks of pastures (squares) are at a single location than when each square is located at a separate location. Nevertheless, during data analysis the

Table 2. Analysis of variance and expected mean squares for cross-over design used to analyze esophageal fistula samples 1 .

\begin{tabular}{|c|c|c|c|c|}
\hline Source & $\mathrm{df}$ & Mean Square & $\mathrm{E}\left(\right.$ Mean Square) ${ }^{2}$ & F-test \\
\hline Square & $(s-1)$ & & $\sigma^{2}+t^{2} \sigma_{\mathrm{S}}^{2}$ & \\
\hline Animal/Square & $s(a-1)$ & & $\sigma^{2}+t^{2} \sigma_{\mathrm{A}(\mathbf{S})}^{2}$ & \\
\hline Period & $(p-1)$ & $\mathrm{MS}_{\mathrm{p}}$ & $\sigma^{2}+t^{2} \Phi P$ & $\mathrm{MS}_{\mathrm{p}} / \mathrm{MS}_{\mathrm{RES}}$ \\
\hline Treatment & $(t-1)$ & $\mathrm{MS}_{\mathrm{T}}$ & $\sigma^{2}+t^{2} \Phi T$ & $\mathrm{MS}_{\mathrm{T}} / \mathrm{MS}_{\mathrm{RES}}$ \\
\hline Residual & $(p-1)(s t-2)$ & $\mathrm{MS}_{\mathrm{RES}}$ & $\sigma^{2}$ & $\mathrm{MS}_{\mathrm{RES}}$ \\
\hline
\end{tabular}

'Treatments and periods are fixed effects while the effects of animals and squares are considered random. 2Expected mean squares. 
Table 3. Analysis of variance and expected mean squares for split-plot design used to analyze hand-clipped samples'.

\begin{tabular}{|c|c|c|c|c|}
\hline Source & $\mathrm{df}$ & Mean Square & $\mathrm{E}\left(\right.$ Mean Squarc) ${ }^{2}$ & F-test \\
\hline Block & $(b-1)$ & . & $\sigma^{2}+\operatorname{tp} \sigma_{\mathrm{B}}^{2}$ & \\
\hline Treatment & $(t-1)$ & $\mathbf{M S}_{\mathbf{T}}$ & $\sigma^{2}+p \sigma_{\mathrm{BT}}^{2}+\mathrm{bp} \Phi \mathrm{T}$ & $\mathbf{M S}_{\mathbf{T}} / \mathbf{M S}_{\mathrm{BT}}$ \\
\hline Block $\times$ Treatment & $(b-1)(t-1)$ & $\mathrm{MS}_{\mathrm{BT}}$ & $\sigma^{2}+\mathrm{p} \sigma_{\mathrm{BT}}^{2}$ & \\
\hline Period & $(p-1)$ & $\mathbf{M S}_{\mathbf{p}}$ & $\sigma^{2}+t \sigma_{\mathrm{BP}}^{2}+b t \Phi P$ & $\mathbf{M S}_{\mathrm{p}} / \mathbf{M S} \mathbf{S P}_{\mathrm{BP}}$ \\
\hline Block $\times$ Period & $(b-1)(p-1)$ & $\mathrm{MS}_{\mathrm{BP}}$ & $\sigma^{2}+t \sigma_{\mathrm{BP}}^{2}$ & \\
\hline Treatment $\times$ Period & $(t-1)(p-1)$ & $\mathbf{M S}_{\mathbf{T P}}$ & $\sigma^{2}+\sigma_{\mathrm{BTP}}^{2}+b \Phi T P$ & $\mathbf{M S}_{\mathrm{TP}} / \mathbf{M S} \mathbf{S T P}_{\mathrm{BT}}$ \\
\hline Block $\times$ Treatment $\times$ Period & $(b-1)(t-1)(p-1)$ & $\mathrm{MS}_{\mathrm{BTP}}$ & $\sigma^{2}+\sigma_{\mathrm{BTP}}^{2}$ & \\
\hline
\end{tabular}

'Treatments and periods are fixed effects while the effects of blocks are considered random.

2Expected mean squares.

square interactions should be tested for significance and the interactions pooled with error only if they are found to be nonsignificant (Federer 1955).

It should also be noted that use of Latin squares or a cross-over design does not provide a means for testing for significant interactions involving the main effects of periods, treatments, or animals. Indeed, an essential assumption for both designs is that main effect interactions are zero. Scheffe (1959) discusses the possible effects that violations of this assumption will have on the analysis. In many experiments, animal $\times$ treatment and animal $X$ period interactions are likely not to be important and are biologically more likely to be nonexistent than are treatment $\times$ period interactions. However, in the event that treatment $\times$ period interactions are of major concern or are believed to be relatively large, both the Latin square and cross-over designs are inappropriate and some other complete or incomplete block design should be used, necessitating the use of additional fistulated animals.

Continuing the example above, the number of blocks $(b)$ possible is set equal to 3 , the number of treatments. Three animals would be required to complete each block since the study contains 3 treatments. Therefore, a total of $9(s \times t)$ animals would be required to sample the pastures using the cross-over design. The analyses shown in Tables 1 and 2 are appropriate only for testing for treatment differences among esophageal samples; they are inappropriate for testing for treatment differences among clipped samples or differences between esophageal and clipped samples. In Table 1 the appropriate error mean square for testing treatment differences is treatment $\times$ square.

\section{Hand Sampling}

Hand-clipped forage samples are also collected during the same periods on the same pastures as the esophageal samples. These samples are generally collected at random by 1 or 2 individuals going from pasture to pasture so it can be assumed that pasture and sampling effects arc independent. The appropriate analysis of variance for the hand-clipped samples is a split-plot in time (Anderson and McLean 1974). The analysis of variance for this design is shown in Table 3 . The block $\times$ treatment interaction (error $A$ ) with $(b-1)(t-1)=\mathrm{df}$ is the correct error term for testing for treatment differences for the hand-clipped samples. This analysis should be used only for testing for differences among clipped samples.

\section{Comparison of Esophageal and Hand Samples}

The comparison of esophageal and hand-clipped samples is not straightforward because the samples were collected using different designs as is apparent by comparing Tables 1 and 3. Therefore, neither the Latin-square design nor the split-plot in time design can be used to assess differences between esophageal and hand-clipped samples; however, these differences can be assessed using paired $t$-tests.

Each individual period/treatment combination (experimental unit) has a pair of measurements: 1 from the hand-clipped sample and 1 from the esophageal-collected sample. These paired measurements can be used to calculate paired differences, differences which are replicated due to the presence of replicated pastures. Standard errors of the difference, $\left(\mathrm{S}_{\mathrm{D}}^{2} / \mathrm{n}\right)^{1 / 2}$, can easily be calculated and the magnitude of specific differences can be tested using paired $t$-tests (Steel and Torrie 1980). Since esophageal and hand-clipped samples are paired within individual experimental units, various types of $t$-tests may be made, under the restrictions that the observations or means used to calculate the differences are truly paired and replicated. Some differences which are not truly paired, such as esophageal/treatment 1 versus hand-clipped/treatment 2, cannot be made.

A paired $t$-test can be used to test the null hypothesis that hand-clipped and esophageal samples are equal. If the alternative hypothesis is that the samples are not equal, a 2-tailed test is used. However, if the alternate hypothesis is that the esophageal samples are higher (or lower) in a particular attribute, a 1 -tailed $t$-test should be used. This analysis can be done over periods using the over period esophageal and hand-clipped sample means per pasture. The $t$-test can be used to determine if esophageal samples differed from hand-clipped samples by treatment or averaged over treatments.

\section{Esophageal $\times$ Hand Sample Interactions}

Differential selectivity occurs when animals select a different diet from the various pasture treatments. Estimates of differential selectivity can be made by analyzing differences between values obtained from hand-clipped and esophageal samples. The differ-

Table 4. Analysis of variance and expected mean squares for randomized complete block design used to analyze mean differences between hand-clipped and esophageal fistula samples ${ }^{1}$.

\begin{tabular}{lllll}
\hline \hline Source & $\mathrm{df}$ & Mean Square & E(Mean Square) \\
\hline Block & $(\mathrm{b}-1)$ & & $\sigma^{2}+\sigma_{\mathrm{B}}^{2}$ \\
Treatment & $(\mathrm{t}-1)$ & $\mathrm{MS}_{\mathrm{T}}$ & $\sigma^{2}+\sigma_{\mathrm{BT}}^{2}+\mathrm{b} \Phi \mathrm{T}$ \\
Block $\times$ Treatment & $(\mathrm{b}-1)(\mathrm{t}-1)$ & $\mathrm{MS}_{\mathrm{BT}}$ & $\sigma^{2}+\sigma_{\mathrm{BT}}^{2}$ \\
\hline
\end{tabular}

'Effects of treatment are fixed while the effects while the effects of blocks are considered random.

${ }^{2}$ Expected mean squares. 
ences per se become the variables analyzed and mean differences for each pasture averaged over periods can then be analyzed in a simple randomized complete block design as shown in Table 4. The appropriate source of error for testing mean differences between esophageal and hand-clipped samples is the block $X$ treatment interaction with $(k-1)^{2} \mathrm{df}$. If the treatment effect is significant the animals differentially selected a better or "different" diet on some treatments than others. This analysis, in essence, tests whether there is a sample collection method by treatment interaction effect by testing the following hypothesis: Ho: $=\Delta^{1}=\Delta^{2}=\Delta^{3}=$ where $\Delta$ is the difference between esophageal and hand-clipped samples. The paired $t$-tests, in contrast, test the hypothesis $\mathrm{Ho}: \Delta^{1}=0, \Delta^{2}=0$, and $\Delta^{3}=0$ or Ho: $=\Delta^{1,2,3}=0$.

\section{Conclusions}

The methods we have presented for assessing differences between samples collected by hand and esophageal fistula are simple and permit the use of a single esophageal animal per pasture. The analyses are statistically correct, allowing valid comparisons among and between esophageal and hand-clipped samples. The statistical procedures permit the testing of the 4 principal hypotheses of esophageal studies: (1) esophageal samples are similar over treatments, (2) hand-clipped samples are similar over treatments, (3) esophageal and hand-clipped samples are similar, and (4) differential selection of diet did not occur among treatments.

\section{Literature Cited}

Allison, C.D. 1985. Factors affecting forage intake by range ruminants. J. Range Manage. 38:305-311.

Anderson, V.L., and R.A. McLean. 1974. Design of experiments: A realistic approach. Marcel Dekker, Inc. New York.

Barth, K.M., and N.T. Kazzal. 1971. Separation of true selective grazing by cattle from effects of the esophageal fistula. J. Anim. Sci. 33:1124-1128.

Brown, M.A., and S.S. Waller. 1986. The impact of experimental design on the application of grazing research results-an exposition. J. Range Manage. 39:197-200.

Campbell, C.M., K.S. Eng, Jr., A.B. Nelson, and L.S. Pope. 1968. Use of the esophageal fistula in diet sampling with beef cattle. J. Anim. Sci. 27:231-233.

Coleman, S.W., and K.M. Barth. 1973. Quality of diets selected by grazing animals and its relation to quality of available forage and species composition of pastures. J. Anim. Sci. 36:754-761.

Federer, W.T. 1955. Experimental design. Macmillan Co. New York, N.Y.

Large, R.V., J.M. Cobby, and R.D. Baker. 1985. The design and conduct of experiments to measure animal and herbage production responses to fertilizer nitrogen under cutting and grazing managements. J. Agr. Sci. Camb. 104:85-94.

Scheffe, H. 1959. The analysis of variance. John Wiley \& Sons, Inc., New York.

Steel, R.G.D., and J.H. Torrie. 1980. Principles and procedures of statistics. McGraw-Hill Book Co., New York.

Stroup, W.W., S.S. Waller, and R.N. Gates. 1986. Exposition on the selection of appropriate experimental design and statistical analysis for pasture improvement research. J. Range Manage. 39:200-207.

t'Mannetje, L. 1978. Measurement of grassland vegetation and animal production. Bulletin 52, Commonwealth Bureau of Pastures and Field Crops, Hurley, Berkshire, England.

Van Dyne, G.M., and D.T. Torell. 1964. Development and use of the esophageal fistula: a review. J. Range Manage. 17:7-19. 